\title{
Participation ahead: Perceptions of Masters degree students on Reciprocal Peer Learning Activities
}

\author{
Catarina Lelis \\ London School of Film, Media and Design \\ University of West London \\ catarina.lelis@uwl.ac.uk
}

\begin{abstract}
Peer Learning is broadly described as the development of knowledge or skills by individuals from similar statutory conditions who are learning from and with each other in both formal and informal ways. There is a considerable amount of published work on peer learning in the context of schools and undergraduate courses but little work has been developed around postgraduate levels, specifically with Masters courses. The goal of the research presented in this paper was to understand how Masters degree students perceive and engage with a peer learning activity set in a taught module. One specialist subject topic from the curriculum was assigned to each student who, during two sessions in regular teaching times, had to perform both as peer tutor and tutee in a reciprocal peer learning approach. Two questionnaires were applied - one for each role the students had to perform. Results reveal that the majority of students considered the peer tutor role undeniably positive; however, while performing as tutees, students expressed skepticism regarding the effectiveness of the approach. As the credibility of peers was evidenced as an issue (when set against these students' high expectations), this paper contends that reciprocal peer learning may not be the most suitable peer learning method for master levels.
\end{abstract}

Keywords

reciprocal peer learning, masters level, student perception, participation

\section{Introduction}

It is commonly held that the quality of lecturers will greatly influence the quality of the courses or modules in which they are involved or which they deliver. Pavlina, Zorica and Pongrac (2011) stated that teacher quality characteristics are divided into three main categories: teacher expertise (the teacher's expertise in his scientific field); teaching competence (which mostly represents the teacher's ability to create a good working atmosphere); and, personal qualities (which influence the quality of teaching, such as being thoughtful, punctual, motivated for work and regularly available for consultations). However, when it comes to leading and preparing a module called "Innovation", taught on a creativity-oriented master course, it is self-evident that quality of teaching should be as important as innovativeness.

As noted in an EU report edited by Ferrari, Cachia and Punie (2009), innovative teaching is strongly grounded in and dependent on information and communication technologies. However, according to the researcher's understanding, while technologies are appropriate tools to help humans reach innovation and creativity, they should not be taken as the main asset or even as a method. Hence, innovative teaching and learning, in the context of this research, has nothing do to with technologies but, rather, more to do with human-centered approaches. Since Participatory 
Design (PD) was one of the topics to be covered in the "Innovation" module, it was selected as the most relevant method in order to conceive the module as a participatory and informed one (which is, per se, an innovation in teaching). Fischer and Ostwald (2002) defined PD as a form of collaborative design in which participants use the information they can access in order to contribute to its transformation into new knowledge, to best propose new contexts and to codesign solutions for end users. These authors argued that when participants are involved in both contribution and in learning activities, they reach a collaborative state called "informed participation" (Brown \& Duguid, 2000).

Master in Arts (MA) students are mature and highly skilled individuals mostly studying alongside keeping a full-time job. They attend their postgraduate courses with a consolidated attitude that undergraduate students do not yet possess. Within a course where identity and values form part of a creativity-oriented standpoint, these students are a priori an "appropriate" group to try out an innovative and collaborative peer learning approach. As such, they should be able to act as cotutors or, inclusively, take the lecturer's place and explore a curriculum topic, teaching to and learning from their peers.

Although there is ample literature exploring peer learning on undergraduate courses, there is little work on the implementation and efficiency of peer learning activities at Masters level. Hence, the research question that guided this work was: How do Masters students perceive and engage with a peer learning session?

This paper is organised in five sections. First, it gives an overview of the literature regarding peer learning in the Higher Education (HE) context. Second, it outlines the research setting before it describes the method used to gather information on the proposed approach. It then presents the findings and a discussion on the outcomes. Finally, a conclusion is drawn presenting the limitations and recommendations for future work.

\section{Literature Review}

Learning with and from peers is a natural human activity. It is part of our animal nature to learn with and from those living around us, and part of our human social nature to be able to develop every day, appropriating languages, accents, signs, expressions, attitudes, emotions, rational and creative new skills and incorporating them into repertoires of knowledge. This way of learning through reciprocal modelling is extensively described in Bandura's Social Learning Theory (Bandura, 1977). Through this process, according to Wenger (1998), individuals incrementally integrate as group members in the community in which they live, work, study and collaborate. But those around may or may not be their peers. The word peer comes from the Latin word par which means equal. In the case of children, peers are other children with whom they have close contact (because they belong to the same group) and with whom they share the same interests, level of development and motivations. Their parents (whom they mimic) are not considered their peers because they do not stand in an equal position. The same happens with students and lecturers students' peers are other students while their lecturers are not.

\section{Defining peer learning}

According to Topping (1996), the interaction between peers that leads to learning and development is Peer Learning (PL) or Peer to Peer Learning. Havnes, Christiansen, Bjørk and Hessevaagbakke (2016) gathered other possible names for the very same construct, including: collaborative/cooperative learning; group mentoring; peer tutoring; supplemental instruction; peer assisted learning; peer assessment; dialogical pedagogy; reciprocal teaching; and classroom talk.

PL has been defined as:

- Students learning from and with each other in both formal and informal ways (Boud, Cohen \& Sampson, 2001); 
- A way of moving beyond independent to interdependent or mutual learning (Boud, 1988);

- The acquisition of knowledge/skills through active helping and supporting among individuals from similar statutory conditions who are not professional tutors (Topping, 2005).

Topping (2005) claimed that PL is usually implemented in schools to improve the performance of at-risk students while Lim (2014) argued that PL serves the purpose of motivating students and raising their commitment to the learning process. In college and university education, PL is used widely in healthcare and medicine contexts and frequently applied to a wide variety of domains (Topping, 2005). Several universities in the UK have promoted similar learning strategies in the last decade, aiming mostly at student retention, academic success and high engagement (Hilsdon, 2014). In fact, student engagement and student satisfaction are pivotal goals for the sector, being linked to the idea of having students as partners:

Engaging students in partnership means seeing students as active participants in their own learning, and although not all active learning involves partnership it does mean engaging students in forms of participation and helps prepare them for the roles they may play in full partnership. Engaging students as teachers and assessors in the learning process is a particularly effective form of partnership.

(Healey, Flint \& Harrington, 2014, p. 8)

Topping (1996) identified different paths to peer learning in the HE context: Same-year dyadic fixed-role tutoring; Same-year reciprocal peer tutoring; Dyadic cross-year fixed-role peer tutoring; Same-year group tutoring; Peer assisted writing; and Peer assisted distance learning. Topping (2005) noted that peer learning used to be implemented as asking the best students to assume a role similar to the one held by professional lecturers, that is, taking their place. According to Boud et al. (2001), this is more instrumental than PL and is better called Peer Teaching. Of particular relevance to the findings of this study, Topping (2005) also revealed that "the differential in levels of ability and interest in such a situation could prove under-stimulating for the helper who was unlikely to gain cognitively from the interactions" (p. 631).

\section{Reciprocal peer learning}

Based on several previous studies, Havnes et al. (2016) noted that, currently, the emphasis has been on more structured PL activities including all students in a participatory and mutual way. Reciprocal PL emphasises the relevance of mutual experiences, acknowledging that students are able to make equal contributions if they are given proper opportunities (Boud et al., 2001). According to Topping (2005), when students take the role of tutors they are expected to learn by teaching while being in a position that their peers will consider as more proximate to theirs. Topping (1996) argued that such activities represent a further cognitive challenge since "just preparing to be a peer tutor has been proposed to enhance cognitive processing in the tutor - by increasing attention to and motivation for the task, and necessitating review of existing knowledge and skills" (p. 324).

It is worth highlighting two relevant findings in this context. First, in a research project developed by Annis (1983), randomly allocated groups of students involved in PL activities revealed that those playing the role of tutors gained more than those in the role of tutees. Second, in another project, Hendelman and Boss (1986) found that, when in the role of tutees, students say that peer learning was as effective as traditional teaching and, once in the role of tutors, they perceived it as more effective than traditional teaching. For these reasons, PL is often promoted as a "Learning by Teaching" technique, grounded on the old saying "to teach is to learn twice" (Topping, 1996, p. 324). 


\section{Advantages and disadvantages of Peer Learning}

Thus, reciprocal PL seems to bring some gains to the students. Besides the cognitive advantages, Topping (1996) highlighted the relevance of social and motivational gains translated in "greater commitment, self-esteem, self-confidence and empathy with others" (p. 325). Boud et al. (2001) contended that, when students are able to value PL activities, they tend to describe them as "challenging, creative, exciting and supportive" (p. 22). These authors also explained that when students first enter a course, engagement activities are extremely important in order to help them mix with a greater number of other students, while increasing their interpersonal, communicational, planning and evaluation skills. Further, Boud et al. (2001) argued that they can do this more easily with their peers, who are other individuals in a similar situation, without any kind of power over each other, using the same language and facing the same level of challenges in the same environment. Regarding this matter, Topping (2005) stated that students may never have deeply understood a concept until the day they have to explain it, "embodying and crystallising thought into language" (p. 637), a factor which will also contribute to reducing the normal asymmetries between tutor and tutee.

Lim (2014) claimed that PL contributes to the development of teamwork, time management, organisational and presentation skills - usually claimed as core transferable skills - as students explore them through exposing and critiquing the curriculum topics by means of participation (Hilsdon, 2014). Hence, PL also prepares students for specific professional contexts because they take responsibility for their own learning journey (Boud et al., 2001).

There are also some drawbacks in PL. For example, Boud et al. (2001) claimed that students who have had effective autonomous learning experiences can find PL uncomfortable. On the other hand, those who are used to formal and traditional approaches (like teacher-centered learning) may have difficulties in understanding the real value of such a different method; they believe they are supposed to learn from the lecturer, being skeptical about the ability of their peers to either teach them anything, or teach them without flaws (Boud et al., 2001).

\section{Research setting}

The main purpose of the study described in this paper was to investigate Masters students' perceptions towards what was considered a different and participatory peer learning approach in a one-year MA course. A same-year reciprocal peer learning approach (see Topping, 1996) was adopted in an "Innovation" module delivered throughout 13 weeks in two Masters courses at the School of Film, Media and Design at the University of West London, UK.

The students in the study shared an advanced level of expertise and the majority of them had previous or ongoing work experience. Because these Masters courses are still relatively new, running for three years at time of writing, the class size was small, with a maximum of 11 students. However, due to their diversity in previous academic backgrounds (the majority of these students come from a social and human sciences background, only two had degrees in the creative or artistic domains) and various ethnic origins (two Asians, one British African, three British, three Europeans and two Arabs), this cohort was considered appropriate for the purpose of this study, considering Chanock's (2004) insights on how different cultural backgrounds can affect students' autonomy and responsibility towards learning. There was some homogeneity among these students: out of the 11, 10 were female and all were within the same age range (21-28 years old). Hence, all are to be considered mature students, subject to the influence of adult learning factors which Knowles (1984) identified as:

- autonomy, as the adult learner is self-directing;

- $\quad$ previous experience, which constitute rich resources for the learning process;

- role models' impact on adults' readiness to learn;

- engagement with learning activities, which in adults are more effective if life-centered, task-centered, or problem-centered; and

- $\quad$ intrinsic motivators, such as self-esteem, self-confidence, self-actualisation, recognition and better quality of life. 
Students were told they would be involved in a collaborative role-taking activity and that, at some point, each one of them would be a tutor for 15 minutes, while the others would take the role of tutees. Their participation in the peer learning activity was not part of the assessment strategy and they had competing demands from other modules. For these reasons, the additional effort required was carefully managed. For example, since the activity would be focused on the Innovation module's contents and since each student has an Innovation project to submit for assessment (linked to their Masters Project), they were given a list of Innovation topics from which they were to select two topics that, in some way, would have the most significant impact on their individual ongoing projects. The topics were: The Internet of Things, Augmented Reality, Semantic Web, Social Innovation, Participatory Design, Open Innovation, Open-Source and Creative Commons, Protecting Innovation, Online start-up culture, Sustainability, and Measuring Innovation. The selection of topics was extraordinarily simple: each student had very diverse research interests, picking the topics they considered either more inspirational or pragmatic. The few overlapping intentions were resolved distributing topics in a fair and consensual manner.

Finally, each student's topic would serve as the basis to explore their preferred subject from the perspective of Innovation and would, critically, be presented to their peers in two reciprocal micropeer teaching sessions (six students in the first session and five students in the second one). A fit to the module's specific learning outcomes (LO) was guaranteed, namely to LO3, "present critical and systematic information and argue a position using relevant media forms to achieve acceptance of a proposition," and LO4, "critically understand and systematically engage with key contextual, theoretical and critical discourses at the forefront of innovation discipline."

\section{Method}

This was a small-scale study, following an interactive design as proposed by Maxwell (2009) which evolves according to the findings and results of the techniques used to collect and analyse data, resulting in a two-iteration research. Hence, after a set of questionnaires, ad hoc interviews were introduced for verification and validation purposes but remained part of an integrated strategy.

The context in which PL activities happen is one of the most relevant design features to be considered. Within such an important dimension, and to implement PL properly, Topping's (2005) variables were considered and contextualised to this study (see Table 1). 
Table 1. Peer learning activity design (after Topping, 2005)

\begin{tabular}{|c|c|}
\hline Variable (Topping, 2005) & Contextualised in this study \\
\hline Curriculum content & A set of suggested Innovation related topics. \\
\hline Contact constellation & $\begin{array}{l}\text { Masters students }(n=11) \text { in reciprocal peer learning distributed } \\
\text { by two sessions. }\end{array}$ \\
\hline Year of study & Same-year of study. \\
\hline Ability & $\begin{array}{l}\text { Peer tutors had superior interest on a small and specific part of } \\
\text { the curriculum and selected one of the suggested topics. }\end{array}$ \\
\hline Role continuity & Reciprocal switching roles, namely, as tutor and tutee. \\
\hline Time & $\begin{array}{l}\text { Regular teaching times in order to guarantee the inclusion and } \\
\text { participation of students with fulltime employment; each peer } \\
\text { tutor was required to prepare a } 15 \text { minutes session (lecture, } \\
\text { workshop, game, or any other activity). }\end{array}$ \\
\hline Place & $\begin{array}{l}\text { The regular lecture room guaranteeing minimum comfort to and } \\
\text { familiarity for the students. }\end{array}$ \\
\hline Tutor characteristics & $\begin{array}{l}\text { Each peer tutor was an ordinary student without any } \\
\text { distinctiveness. }\end{array}$ \\
\hline Tutee characteristics & $\begin{array}{l}\text { Each peer tutee was an ordinary student without any sort of } \\
\text { specific need. }\end{array}$ \\
\hline Objectives & $\begin{array}{l}\text { A combination of formal academic cognitive gains and } \\
\text { affective/social skills development. }\end{array}$ \\
\hline Voluntary or compulsory & $\begin{array}{l}\text { Students were told this would be part of their timetabled } \\
\text { sessions, aiming at a participatory approach, but not mandatory. }\end{array}$ \\
\hline Reinforcement & $\begin{array}{l}\text { Although there was an intrinsic motivation (since their topics } \\
\text { were linked to their research interests), in the last session } \\
\text { students were presented with a big box of fruit gums. }\end{array}$ \\
\hline
\end{tabular}

Since each student would have to perform two different roles, two questionnaires were prepared, with the aim of collecting impressions on each of their performances. The questionnaires used a 15 point Likert scale, in which 1 would represent the lowest value and 5 the highest. Because these questionnaires were distributed at two different times, in order to guarantee both anonymity and so that each respondents' first questionnaire would be linked to the second, they were asked to include an avatar or nickname. Since only a minority of these students were English native speakers (the three British and the British African), questions were carefully designed in order to avoid ambiguity and misinterpretation. Nevertheless, it is worth mentioning that as part of their application, all non-native English students met the University's English language requirement via the International English Language Testing System (IELTS). Students were also asked to write down comments whenever they thought it could clarify their evaluation.

\section{“Being the Peer Tutor” Questionnaire}

Before the first session started, students were asked to fill the "Being the Peer Tutor" questionnaire. As Topping (1996) had highlighted the importance of preparation, the students were asked to evaluate how they felt about having to prepare a peer learning session and what impact 
they believe it would have on their specific projects' interests and transferable skills, grounded on the cognitive processing development. According to Lim (2014), procrastination is a common problem among university independent students and, because peer-tutors would have to understand and prepare their topics well enough in order to share them to their peers, this questionnaire included a question about the time necessary for the preparation of their topic using the number of weeks as a measure of time. A question was also asked concerning the responsibility peer tutors believed this would represent for them. Finally, students were asked about the amount of research they had to undertake and, regarding the learning process, if they consider to have learned more about the topic by preparing and having to crystallise it for their colleagues than if they would by having a traditional lecture.

\section{“Being the Peer Tutee” Questionnaire}

By the end of the second PL session, students were asked to fill the "Being the Peer Tutee" questionnaire. They were now prompted to scale how they had engaged with their peers' topics and their relevance to their ongoing studies/projects, how comfortable they felt on being taught by a peer, and how they would classify PL activities within their postgraduate experience. They evaluated their colleagues' performance as well, using clarity, engagement and domain and relevance of the topic as pivotal criteria. Once more, they were asked if they consider to have learned more about the topic by having it presented by a colleague, than if they would by having a traditional lecture.

\section{Findings and Discussion}

Of the eleven students in the study, the majority $(n=9)$ participated regularly in the two scheduled PL sessions performing as both tutor and tutee. The students presented their topics making use of expository methods, with a clear tendency shown to deliver knowledge (the traditional learning approach) rather than developing it (exploring different methods, techniques and tools, to which they have already been exposed in several modules within the master course). Nevertheless, three students were able to manage triggering and engaging questions encouraging peer participation.

\section{The questionnaires}

There were as noted, two questionnaires, respectively related to being a tutor and a tutee. There were 9 respondents to the questionnaires.

\section{Being a peer tutor}

While in the role of tutor, students revealed they felt very responsible on conveying the "proper information" about their topic. Their thoughts were clearly linked to their perception of what it means to be a MA student, in an obvious comparison with what might have been their performances in undergraduate learning contexts. Further, they believe a postgraduate interaction between tutor and tutees needs to be more formal and intense hence they are relied upon to present correct/accurate information. One student commented that "I may be the only source my peers will refer to when they are willing to know about that specific subject topic," making clear that the MA status is quite relevant for them.

Most found it easy to cope with their assigned topic (eventually considering it to be more interesting than what they expected in the first place). Gathering the information to prepare their PL activities took them (on average) two to three weeks, revealing a considerable investment of their time and a relatively low level of procrastination.

Most found important connections between their topic and their own Masters' project interests, and all believed that they had learnt more than expected from this experience. When asked about the relevance of their topic for their peers' Masters' projects, responses were varied. However, the majority tended to consider that their up-to-date and future-oriented topics would have direct and/or indirect impacts on their colleagues' research interests. Regarding their social competence, 
communication skills and self-esteem, only one student considered the PL sessions as making little contribution.

The majority of students were happy with their own overall performance. When asked on the efficiency of PL, considering a learning by doing approach compared to a traditional lecture, five out of nine students considered it undeniably more positive and four were not entirely sure about it, but there were no objectively negative responses.

\section{Being a peer tutor}

As tutees, all stated that it was easy to engage with their colleagues' topics and that their peer tutors were properly engaged with their presentations and content. Seven of the nine students said they felt more comfortable and open being tutored by a peer as opposed to being taught by a lecturer; only two students did not feel that way.

Not surprisingly, when asked to what degree they felt that being tutored by a peer made them feel somehow inferior, only two students responded they were sensing some sort of inferiority during PL. However, those feeling less comfortable among their peers are not the same individuals as those who experienced an inferiority feeling. This leads the researcher to believe that one, or possibly two questions, was/were not clear enough or the students misinterpreted them.

All students perceived their relative importance as active participants in the sessions and considered their peers' topics to be relevant or very relevant, both to their Innovation and to their Masters' projects. When asked if they considered having learnt more being tutored by their peers as opposed to being tutored by a lecturer, only one student believed to have learned less, three students considered to have learned more, but five out of nine were not sure about its efficacy.

\section{The interviews}

The questionnaires had revealed some uncertainty around PL among this specific cohort of students. The responses had suggested that students were able to experience a positive learning situation while being tutors (learning by doing), while presenting a more defensive or even skeptical attitude on switching to peer tutees. This finding reiterated Annis's (1983) and Hendelman and Boss's (1986) findings. However, in order to deepen and better understand these results, three of the PL participants were randomly selected and informally asked two questions:

1. Why do you think five out of nine students believe learning by doing is more efficient than traditional learning with a lecturer, whereas only three considered learning with their peers to be more efficient than traditional learning with a lecturer?

2. Since only a minority considered learning with their peers to be more efficient than traditional learning with a lecturer, why do you think the majority of students considered that they feel more comfortable and open being tutored by a peer, as opposed to being taught by a lecturer?

The interviewees believed that the students who recognise learning by doing as a positive practice were able to collaborate outside their comfort zone, exploring topics that were not directly related to their field of expertise (from their BA degree or previous work experiences), having to put considerable background effort in beforehand and, consequently, learning - an idea that is entirely in line with the existing literature.

The interviewees said that those uncertain on the efficiency of learning with their peers may have a more conservative perspective on what/how learning should be, perhaps seeing the tutor as the "fountain of knowledge," as someone "experienced and certified" and able to provide them with "added-value which goes beyond a simple Google ${ }^{\circledR}$ search". Interestingly, and perhaps counterintuitively, one of the British students (presumably exposed to a more dynamic and less conservative learning environment if compared to peers with other nationalities) mentioned the fact that they are paying to take the course and, for that reason, they expect learning activities to be trustful. In short, learning with peers was not considered to be efficacious due to a matter of trust on peers' capabilities (cf. Boud et al., 2001). 
Regarding the second question, the interviewed students simultaneously revealed some amusement and confusion, since it presented two opposite streams. They verbalised possible reasons such as "We're among friends," "It's easier to ask if we don't understand" or "We're on the same learning journey, using the same language," reinforcing again the collected positions in the literature review.

\section{Conclusion}

While this study drew from a small sample in a specific setting, it can be contended that peer learning (PL) works because knowledge is not something poured into an individual's head by someone considered a specialist; it is, rather, something built by the individuals themselves. Peers can give feedback along this learning process and, in fact, it seems that these can do this better than the so-called experts, simply because they tend to be more similar to the other than the experts are.

PL also helps people engage with others and to communicate their ideas in a more confident way, thus developing their non-cognitive transferable skills. However, in the case of the selected postgraduate students who took part in this study, the reciprocity of PL was not as efficient as expected. Students did not find as many advantages on performing the peer tutee role as those they could enumerate by having experienced being a peer tutor.

This may be connected to some of the limitations in this small-scale study. An obvious limitation is that the participants' previous learning experiences (Ginns, Prosser \& Barrie, 2007) were not verified. Yet, according to the results, it is possible to infer that the majority only had contact with traditional learning activities during their undergraduate courses.

The one-year MA students in this study with previous conventional learning journeys shared a context in which they no longer have more advanced peers representing some sort of authority. In this instance, same-year reciprocal PL practices may not thus be the best approach since all were equally "freshers." Hence, they did not recognise in their peers - with diverse backgrounds (in some cases without any previous and explicit education in their current topic or research area) - the expected credibility, consolidated knowledge and the usual traditional hierarchy they would expect a tutor to bring to a learning moment. Inviting these students to peer review their undergraduate colleagues, or including a "veteran" peer tutor (such as an alumni), for trust building purposes, may be alternatives to consider.

Another topic not comprehensibly addressed in this study was the students' different cultural backgrounds, which may affect their classroom experience and expectations. Students' reluctance to being taught by their peers, because they are not trustworthy, reveals conservative views of what "quality" learning and teaching is and should be, which can be influenced (or not) by the student's culture of origin. It is likely that some cultural transformations would be necessary in order to successfully implement PL (Hilsdon, 2014) and these most certainly would have to start in the early years of schooling. However, learning by doing is a path that should be widely embedded and that can be explored without carrying tutees' frustrations. MA students could be more often invited to prepare a topic they would deliver/present to their same subject area undergraduate peers. Inclusively, they could become important elements on their younger colleagues' assessment process, hence developing evaluation and critical argumentative skills.

Moreover, it should be highlighted that MA students with a project-orientated focus, as is the case (rather than an academic dissertation focus) are being prepared to be highly specialised individuals within a certain professional domain. Hence, having an active and participatory element in PL activities may constitute an enormous influential and differentiation factor for these students, when having to put together a soft skills, human-centered Curriculum Vitæ. 


\section{Acknowledgement}

The collaboration of the students enrolling the two MA courses in the areas of Advertising and Branding, in the University of West London, in the academic year of 2015/2016, and the help and support of Dr. Jannie Roed, are gratefully acknowledged.

\section{References}

Annis, L.F. (1983). The processes and effects of peer tutoring, Human Learning. 2(1), 39-47.

Bandura, A. (1977). Social learning theory. New York: General Learning Press.

Boud, D. (1988). Moving towards autonomy. In D. Boud (Ed.), Developing student autonomy in learning (2nd ed., pp. 17-39). London: Kogan Page.

Boud, D., Cohen, R. \& Sampson, J. (2001). Peer learning in higher education: Learning from and with each other. London: Kogan Page.

Brown, J., \& Duguid, P. (2000). The social life of information. Boston, MA: Harvard Business School Press.

Chanock, K. (2004). Autonomy and responsibility: same or different? Proceedings of the Independent Learning Conference 2003, University of Melbourne, Melbourne, Australia. Retrieved from https://www.independentlearning.org/uploads/100836/ila03_chanock.pdf

Ferrari, A., Cachia, R. \& Punie, Y. (2009). Innovation and creativity in education and training in the EU member states: Fostering creative learning and supporting innovative teaching. Luxembourg: European Commission Joint Research Centre (Institute for Prospective Technological Studies). Retrieved from ftp://ftp.jrc.es/users/publications/public/EURdoc/JRC52374_TN.pdf

Fischer, G. \& Ostwald, J. (2002). Seeding, evolutionary growth, and reseeding: Enriching participatory design with informed participation. In T. Binder, J. Gregory, \& I. Wagner (Eds.), Participatory Design Conference (PDC'02), 2002, Malmö University, Sweden. Retrieved from http://13d.cs.colorado.edu/ qgerhard/papers.html

Ginns, P., Prosser, M. \& Barrie, S. (2007). Students' perceptions of teaching quality in higher education: The perspective of currently enrolled students. Studies in Higher Education, 32, 603-615.

Havnes, A., Christiansen, B., Bjørk, I. T., \& Hessevaagbakke, E. (2016). Peer learning in higher education: Patterns of talk and interaction in skills centre simulation. Learning, Culture and Social Interaction, 8, 75-87.

Healey, M., Flint, A., \& Harrington, K. (2014). Engagement through partnership: Students as partners in learning and teaching in higher education. Retrieved from https://www.heacademy.ac.uk/system/files/resources/engagement_through_partnership.pdf

Hendelman, W.J., \& Boss, M. (1986). Reciprocal peer teaching by medical students in the gross anatomy laboratory. Journal of Medical Education, 61(8), 674-80.

Hilsdon, J. (2014). Peer learning for change in higher education. Innovations in Education and Teaching International, 51, 244-254.

Knowles, M. S. (1984). Andragogy in action. San Francisco, CA: Jossey-Bass.

Lim, L. L. (2014). A case study on peer-teaching. Open Journal of Social Sciences, 2, 35-40.

Marquardt, M., \& Waddill, D. (2004) The power of learning in action learning: A conceptual analysis of how the five schools of adult learning theories are incorporated within the practice of action learning. Action Learning: Research and Practice, 1(2), 185-202. doi: $10.1080 / 1476733042000264146$

Maxwell, J. A. (2009). Designing a qualitative study. In L. Bickman \& D. J. Rog (Eds.), 
Handbook of Applied Social Research Methods (pp. 214-253). Thousand Oaks, CA: Sage. Retrieved from https://www.corwin.com/sites/default/files/upm-binaries/23772_Ch7.pdf

Pavlina, K., Zorica, M. B. \& Pongrac, A. (2011). Student perception of teaching quality in higher education. Procedia Social and Behavioral Sciences, 15, 2288-2292.

Topping, K. J. (1996). The effectiveness of peer tutoring in further and higher education: A typology and review of the literature. Higher Education, 32, 321-345.

Topping, K. J. (2005). Trends in Peer Learning. Educational Psychology, 25, 631-645.

Wenger, E. (1998). Communities of practice: Learning, meaning, and identity. Cambridge, MA: Cambridge University Press.

Copyright $\odot 2017$ Catarina Lelis 